\title{
Influence of Unified Power Flow Controller on Flexible Alternating Current Transmission System Devices in $\mathbf{5 0 0}$ kV Transmission Line
}

\author{
Aamir Farooq \\ School of Electrical Engineering, Shandong University, Jinan, China
}

Email address:

aamirfarooq.qaisrani@gmail.com

\section{To cite this article:}

Aamir Farooq. Influence of Unified Power Flow Controller on Flexible Alternating Current Transmission System Devices in $500 \mathrm{kV}$ Transmission Line. Journal of Electrical and Electronic Engineering. Vol. 6, No. 1, 2018, pp. 12-29. doi: 10.11648/j.jeee.20180601.13

Received: December 4, 2017; Accepted: January 9, 2018; Published: February 9, 2018

\begin{abstract}
Power system maintenance and reliability has become an important aspect of research. In this paper the performance of unified power flow controller to control the power flow on the transmission line has been discussed. The voltage source model was used to study the UPFC's behavior in regulating active power, reactive power and voltage curves. Summarized the different results to see the benefits of UPFC in the power system by installing the Power system modeling in MATLAB and installation of UPFC in transmission link.
\end{abstract}

Keywords: Unified Power Flow Controller, FACT Devices, Effect of UPFC on Transmission System

\section{Introduction}

Flexible AC Transmission is an emerging technology in the Power World which uses power electronic devices for reactive compensation. FACTS devices can be utilized to control power flow and enhance system stability. Particularly with the deregulation of electricity market, there is an increasing interest in using FACTS devices in the operation and control of power systems with new loading and power flow conditions. [1]

A better utilization of the existing power systems, to increases their capacity and controllability by installing facts devices becomes imperative. Due to the present situation there are two main aspects which should be considered in using FACTS devices. The first aspect is the flexible power operation according to the power flow control capability of FACTS devices the other aspect is the improvement in transient and steady state stability of power systems. Facts devices are the right equipment to meet these challenges. Facts devices can be effectively utilized for the steady state power control and dynamic control of power systems. [2]

One of the more intriguing and potentially most versatile classes of FACTS device is the Unified Power Flow Controller (UPFC). The UPFC can provide simultaneous control of all basic power system parameters (transmission) voltage, impedance and phase angle). The controller can fulfill functions of reactive shunt compensation, series compensation and phase shifting meeting multiple control objectives. [3] From a functional perspective, the objectives are met by applying a boosting transformer injected voltage and an exciting transformer reactive current. The injected voltage is inserted by a series transformer.

In addition to allow control of the line active and reactive power, the UPFC provides an additional degree of freedom. Its shunt converter operating as a STATCOM controls voltage by absorbing or generating reactive power. Both the series and shunt converters use a Voltage-Sourced Converter (VSC) connected on the secondary side of a coupling transformer. The VSCs use forced-commutated power electronic devices (GTOs, IGBTs or IGCTs) to synthesize a voltage from a DC voltage source. [3]

In this paper the performed UPFC simulation in Simulink (Matlab) in which the power flow control, voltage regulation and stability provided by UPFC has been verified.

\section{Flexible Alternating Current Transmission Systems}

In its most general formulation, the FACTS concept is based on the massive incorporation of power electronics and 
methods onto the high voltage side of the network to make it electronically controllable. [3, 4] Flexible AC Transmission Systems (FACTS) In recent years, power electronics have gained the term for higher power system controllability. Several FACTS devices have been introduced into a variety of applications around the world. Some new equipment is in the practical stage. More research on the FACTS device configuration is discussed in the literature. [5]

In most applications, controllability is used to avoid costintensive or landscape-scale expansion of the power system, such as upgrading or adding substations and power lines. [6]

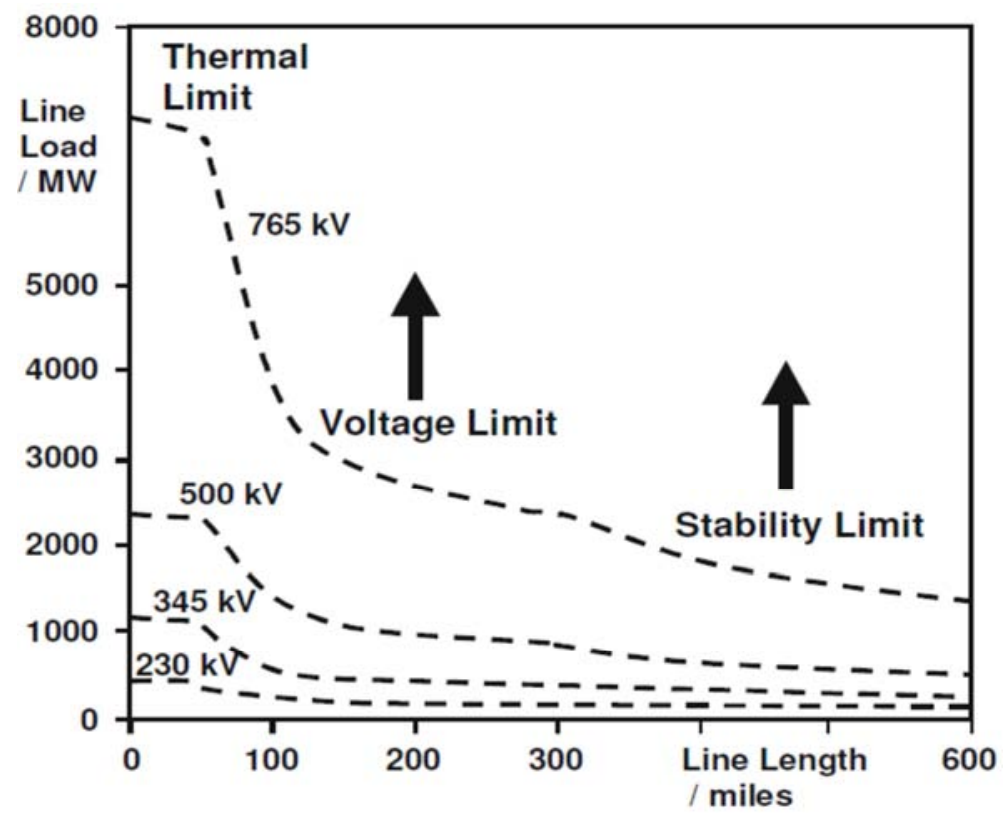

Figure 1. Operational limits of the transmission lines for different voltage levels.

Figure 1 shows the basic idea of a FACTS transmission system. The use of active transmission lines should ideally achieve thermal limits. Voltage and stability limits should be moved by several different FACTS devices. As can be seen, as the length of the line increases, the opportunities for FACTS devices become more and more important. The impact of FACTS devices is through Switch or control shunt compensation, series compensation or phase shift control. These devices work with fast current, voltage or impedance controllers. Power Electronics can shorten the reaction time to less than one second. [6]

\section{An Overview of Facts Controllers}

The development of FACTS devices has begun to evolve as power electronics continue to evolve. High power level devices are already available for high voltage or even maximum voltage converters. The overall starting point is the network element that affects the reactive power or impedance of a part of the power system. Figure 2 shows some of the basic devices separated into regular and FACTS devices.

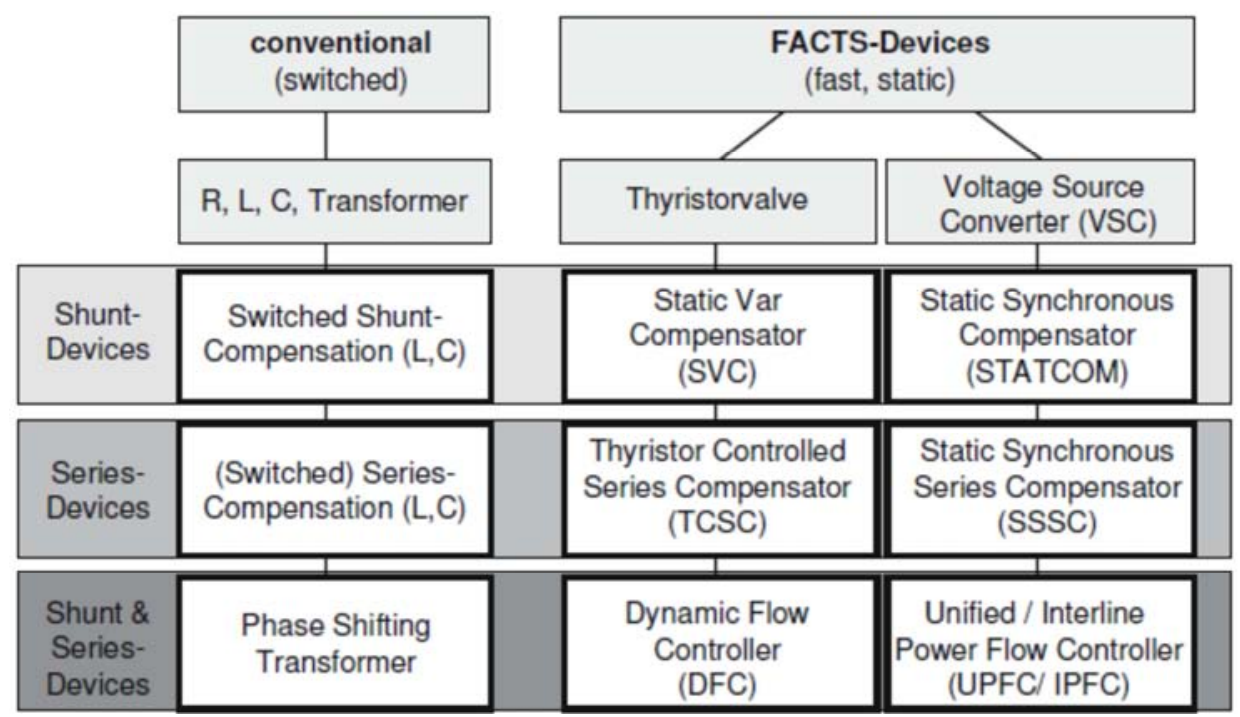

Figure 2. Overview of major fact devices. 
For FACTS, "dynamic" and "static" categories need some explanation. The term "dynamic" is used to indicate the fast controllability of FACTS devices provided by power electronics. This is one of the main differentials of traditional equipment. The term "static" means that the device does not have a movable part like a mechanical switch to perform dynamic controllability. Therefore, most FACTS devices can be static and dynamic as well. [2]

The left column in Figure 2 contains conventional devices that consist of fixed or mechanically switchable components such as resistors, inductors or capacitors, and transformers. The FACTS device also contains these components but uses an additional power electronic valve or converter to switch components in smaller steps or switch modes during the AC cycle. The left column of FACTS equipment uses thyristor valves or transducers. [7]

These valves or transducers have been well known for years. They have low losses due to the lower switching frequency of the converter once per cycle, or simply using thyristors to bridge the valve's impedance.

The right column of FACTS devices now includes more advanced voltage source converter technology based primarily on Insulated Gate Bipolar Transistors (IGBTs) or Insulated Gate Rectifier Thyristors (IGCTs). Due to the pulse width modulation of the IGBT or IGCT, the voltage source converter provides a freely controllable voltage of amplitude and phase. The high modulation frequency allows low harmonics in the output signal, even compensating for interference from the network. The disadvantage is that with the switching frequency increases, the loss is also increasing. So a special converter design is needed to make up for this. In each column, elements can be constructed according to their connection to the power system. Shunt device is mainly used for reactive power compensation and voltage control. SVC provides smoother and more precise control than mechanical switching compensation. It improves the stability of the network and adapts to new situations. STATCOM goes one step further to improve power quality and prevent it from dropping and blinking. [8]
This series of equipment is to compensate reactive power. Because of their effect on the effective impedance of the line, they have an effect on the stability and current. These devices are installed on the platform in series with the production line. Most manufacturers will be series compensation (usually used for fixed configuration) as a FACTS device. The reason is that most components and system setup require the same knowledge as other FACTS devices. In some cases, the series compensator is protected by a thyristor bridge. The application of TCSC mainly to ease the oscillation between the regions, thereby improving the stability, but also have a certain impact on the trend. [9]

The SSSC is by no means a device built on the transmission level, as series compensation and the TCSC are meeting all the requirements of today and are more costeffective. However, the power converter family of applications has implemented power quality applications at the power distribution level, such as ensuring voltage dips and flicker in the plant feed. These devices are known as dynamic voltage restorers (DVRs) or static voltage restorers (SVRs). [10]

It is increasingly important to have FACTS equipment offload and in-line configuration. These devices are for power controllable power. The higher volatility of energy flows due to energy market activity requires more flexible use of transmission capacity. The power flow control device diverts the power flow from the overloaded part of the power system to the area with free transmission capacity. $[9,10]$

\subsection{Working Principle of Unified Power Flow Controller}

The unified power flow controller is the combination of two back to back converter named as VSC1 and VSC2. They are operating from a DC link specified by a dc storage capacitor. These system operate as an ideal ac to ac converter. The real power can independently flow either in direction between the ac terminals of the two converter and each converter can freely generate or absorbs reactive power as its own output terminal.

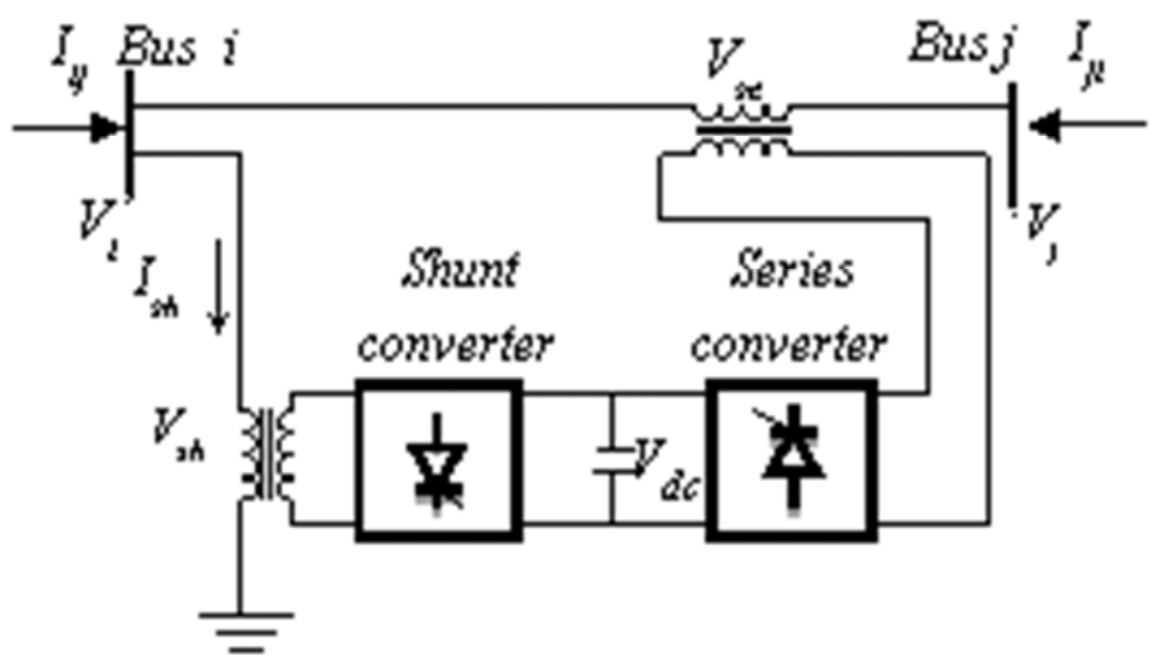

Figure 3. Basic structure of Unified Power flow Controller. 
One VSC is linked in shunt to the transmission line via a shunt transformer and other one is connected in series through a series transformer. [11] The DC terminal of two VSCs is connected and this creates a path for active power exchange between the converters. VSC specify the main function of UPFC by injecting a voltage with controllable magnitude and phase angle in series with the line via an injection transformer. This injected voltage act as a synchronous ac voltage source. The transmission line current flows through this voltage source resulting in reactive and active power exchange between it and the ac system. The reactive power generated at the Dc terminals is exchanged internally by the converter. The real power exchanged at the ac terminal is converted into dc power which appears at the dc link as a real power required. And VSC1 is to supply or absorb the real power required by converter 2 at the common dc link to support real power exchange resulting from the series voltage injection. This de link power demand of VSC2 is converted back to ac by VSC1 and coupled to the transmission line bus via shunt connected transformer. In addition, VSC1 can also generate or absorb controllable reactive power if it is demand and thereby specify independent shunt reactive compensation for the line. [12]

Thus VSC1 can be operated at a unity power factor or to be controlled to have a reactive power exchange with the line independent of the reactive power exchanged by VSC1. Obviously, there is no reactive power flow through the UPFC dc link.

\subsection{Phasor Diagram Representation}

Single phase circuit representation is given below with UPFC installed in the power system (Figure 4). The voltages at the midpoint of transmission line is marked as VM, whereas the voltage injected by UPFC with controllable magnitude and phase is marked as Vc.

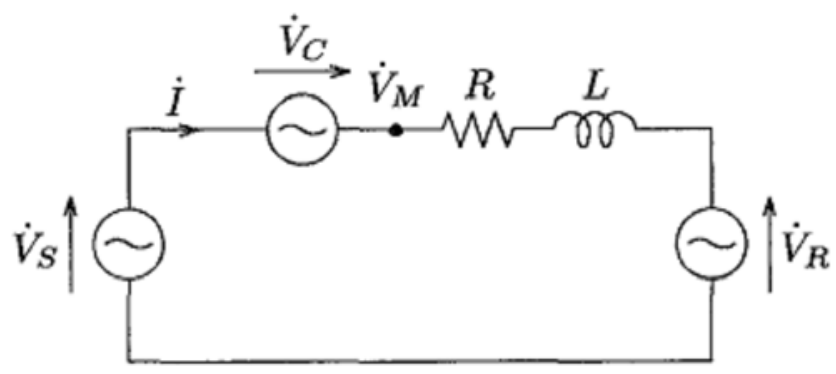

Figure 4. Single phase equivalent circuit.

The shunt inverter in UPFC is operating in such a way to inject a controllable current IC into the transmission line. This current consists of two components with respect to the line voltage: $[13,14]$

1) Real or direct component Id

2) Reactive or quadrature component Iq

The following phasor diagram is well explaining the effect of direct and quadrature components.
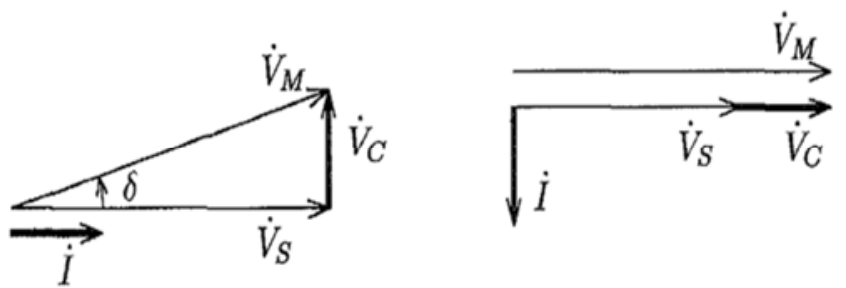

Figure 5. (a) Active/Reactive Power control (b) Voltage regulation.

\begin{tabular}{|c|c|c|c|c|c|}
\hline & $\begin{array}{l}\text { Load Flow } \\
\text { Control }\end{array}$ & $\begin{array}{l}\text { Voltage } \\
\text { Control }\end{array}$ & $\begin{array}{l}\text { Transient } \\
\text { Stability }\end{array}$ & $\begin{array}{l}\text { Dynamic } \\
\text { Stability }\end{array}$ & \\
\hline svc & 0 & 000 & 0 & 00 & 0 \\
\hline STATCOM & 0 & 000 & 00 & 00 & 00 \\
\hline TCsc & 00 & 0 & $\mathrm{OOO}$ & 00 & ( \\
\hline UPFC & 000 & 000 & 00 & 00 & \\
\hline
\end{tabular}

Figure 6. Comparison of UPFC with other Facts techniques.

\section{Simulations and Results}

\subsection{To Relieve Power Congestion on a 500/230 kv Grid}

UPFC is used to control the power flow in a $500 \mathrm{kV} / 230$ $\mathrm{kv}$ transmission system. The system is connected in a loop configuration and consists essentially of five buses (B1 to B5) interconnected by transmission lines (L1, L2, L3) and two $500 \mathrm{kv} / 230$ transformer sets $\operatorname{Tr} 1$ and $\operatorname{Tr} 2$. The two power plants on the $230 \mathrm{kV}$ system generate a total of 1,500 megawatts of power that is transmitted to a 500,000 volt 15,000 MVA equivalent circuit and a 200 MW load connected to the bus B3. Factory models include speed regulators, excitation systems, and power system stabilizers (PSS). In normal operation, the $1200 \mathrm{MW}$ generating capacity of the \# 2 \# power plant is mostly output to $500 \mathrm{kV}$ equivalent through three 400-MVA transformers connected between buses B4 and B5. 


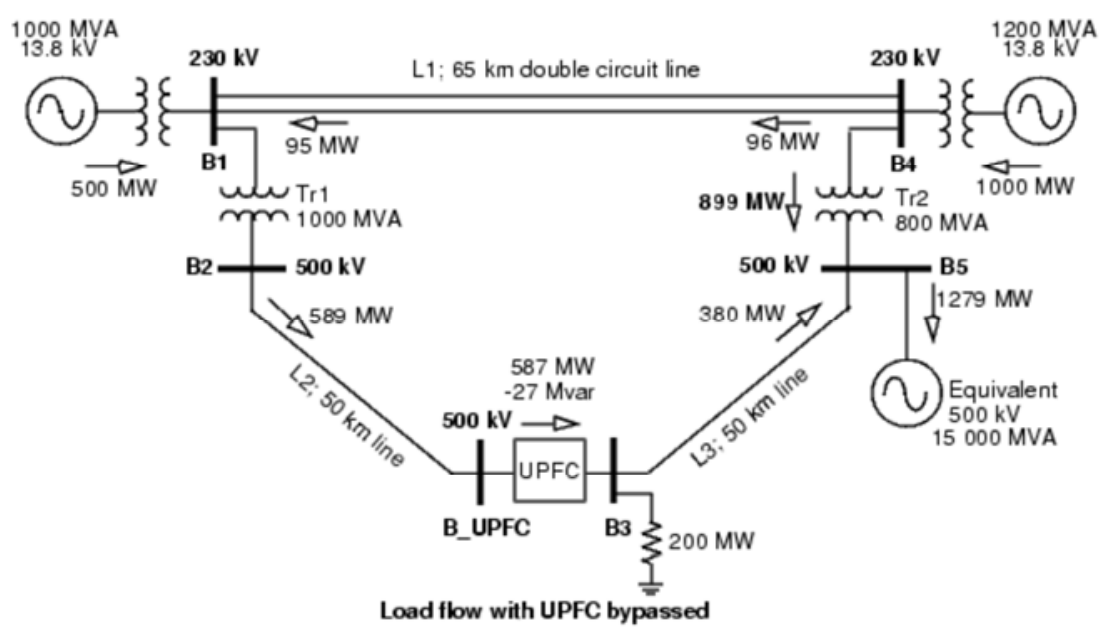

Figure 7. Case study.

Using the load flow option of the power gui block, the model has been initialized with plants \#1 and \#2 generating respectively $500 \mathrm{MW}$ and $1000 \mathrm{MW}$ and the UPFC out of service (Bypass breaker closed or simply, $1^{\mathrm{ee}}$ ). The resulting power flow obtained at buses B1 to B5 is indicated by numbers on the circuit diagram. The load flow shows that most of the power generated by plant \#2 is transmitted through the 800-MVA transformer bank (899 MW out of $1000 \mathrm{MW})$, the rest (101 MW), circulating in the loop. Transformer $\operatorname{Tr} 2$ is therefore overloaded by 99 MVA. The demonstration illustrates how the UPFC can relief this power congestion.

The UPFC located at the right end of line $\mathrm{L} 2$ is used to control the active and reactive powers at the $500-\mathrm{kV}$ bus B3, as well as the voltage at bus B_UPFC. It consists of a Phasor model of two 100-MVA, IGBT-based, converters (one connected in shunt and one connected in series and both interconnected through a DC bus on the DC side and to the AC power system, through coupling reactors and transformers). Parameters of the UPFC power components are given in the dialog box. The series converter can inject a maximum of $10 \%$ of nominal line-to-ground voltage $(28.87$ $\mathrm{kV}$ ) in series with line L2. The numbers on the diagram show the power flow with the UPFC in service and controlling the $\mathrm{B} 3$ active and reactive powers respectively at $687 \mathrm{MW}$ and 27 Mvar.

\subsection{SIMULATION of 500/230 KV with Grid Without UPFC}

This is the Simulink model of above 500/230kv grid station. Effect of UPFC is studied such that first it is simulated without UPFC and active power on all 5 buses is noted. Then UPFC is brought into the system and active power is again noted in a similar fashion. The following is the simulation of the above example without UPFC. Graphs of active power and reactive power are shown. Moreover, active power is also mentioned on the buses in the diagram.

\subsection{Simulation Result}

Active Power (MW) along y axis on bus no 1 to bus no 5

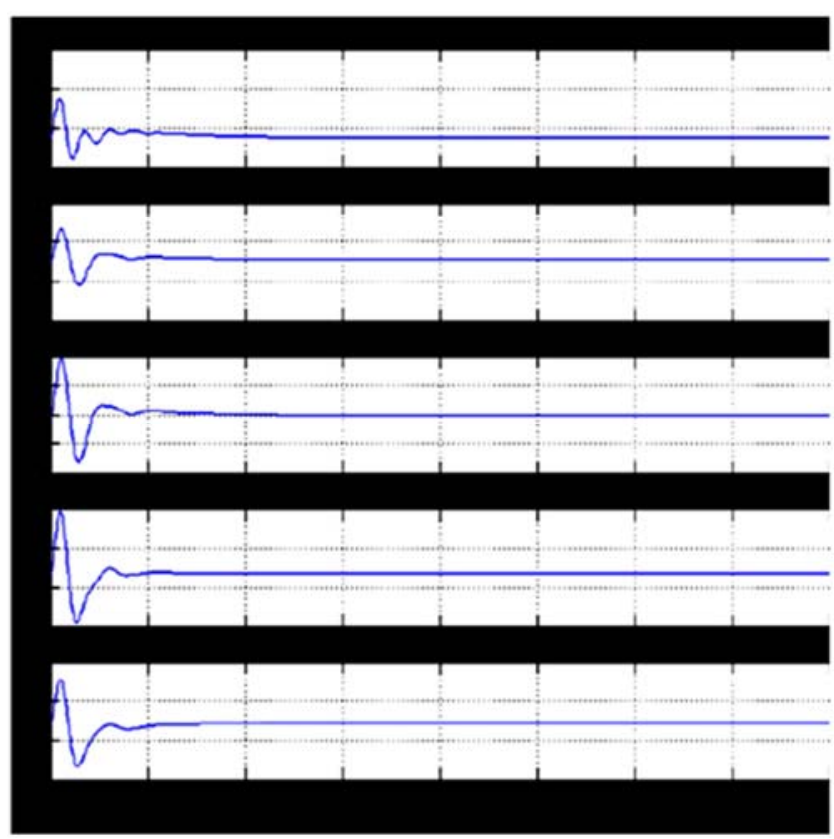

Figure 8. Active Power without UPFC.

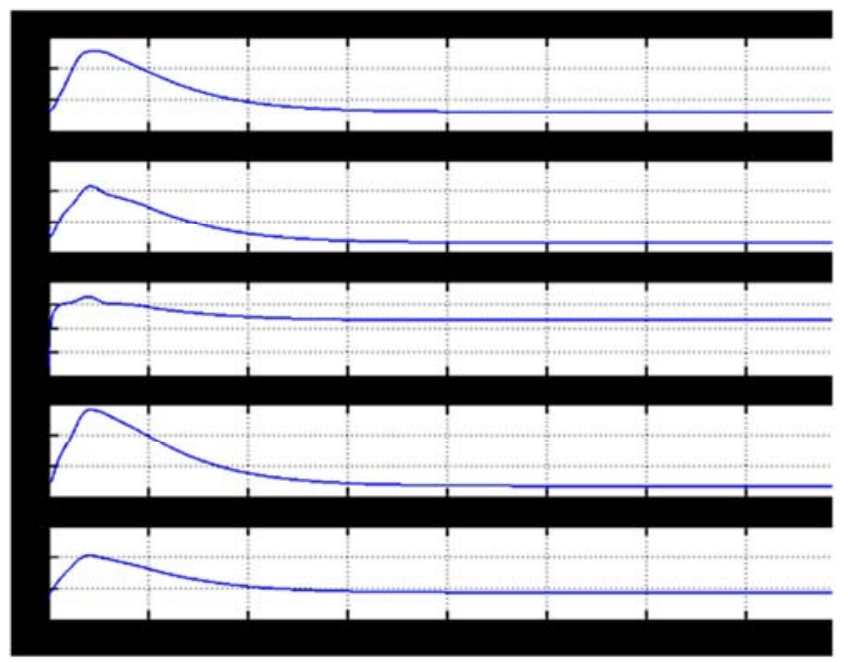

Figure 9. Reactive Power Metering with respect to time (Without UPFC). 


\subsection{Simulation of 500/230 $\mathrm{kV}$ Grid with UPFC}
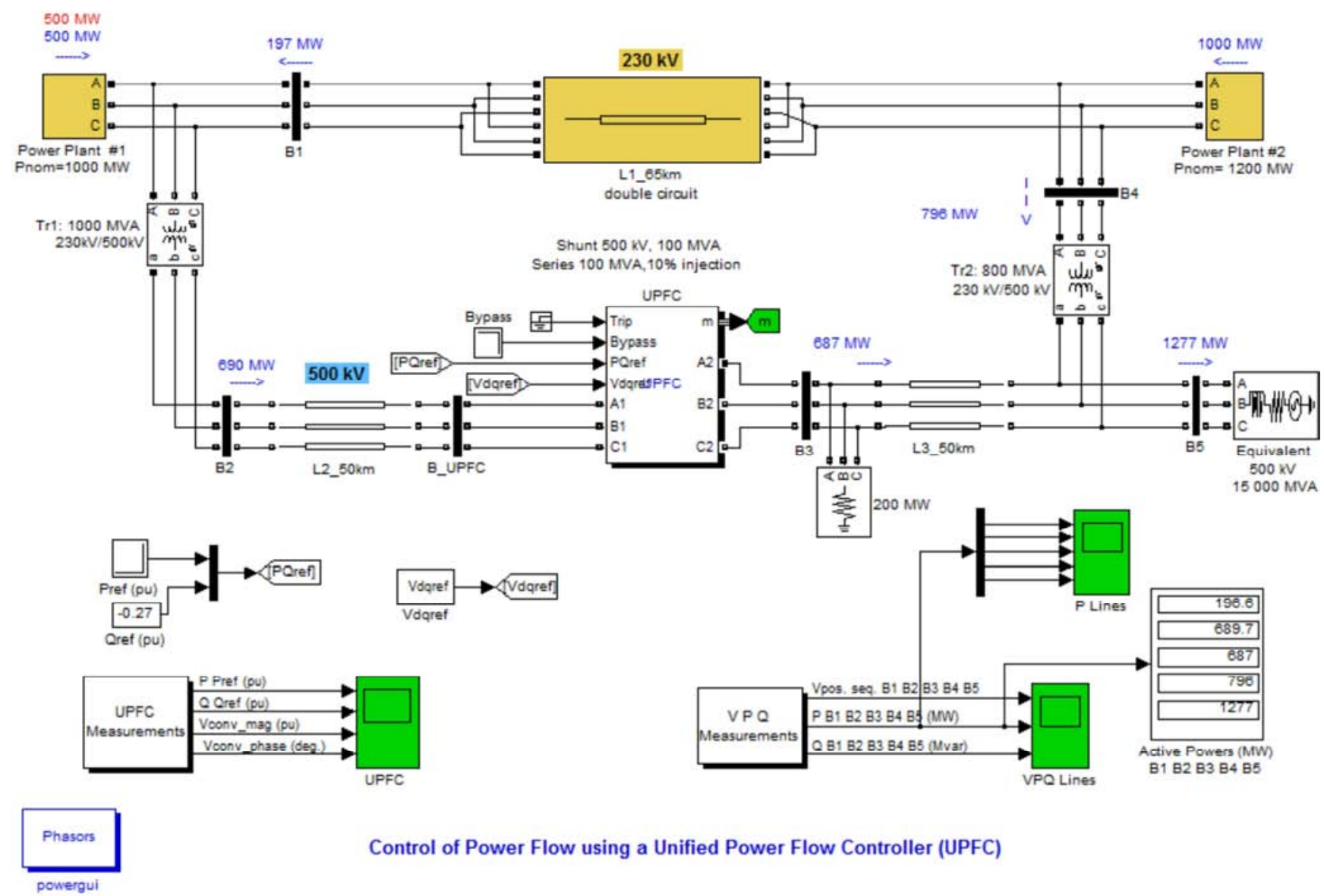

Control of Power Flow using a Unified Power Flow Controller (UPFC)

Figure 10. System modeled with UPFC.

\subsection{Simulation Results}

Active Power (MW) along y axis on bus no 1 to bus no 5 respectively

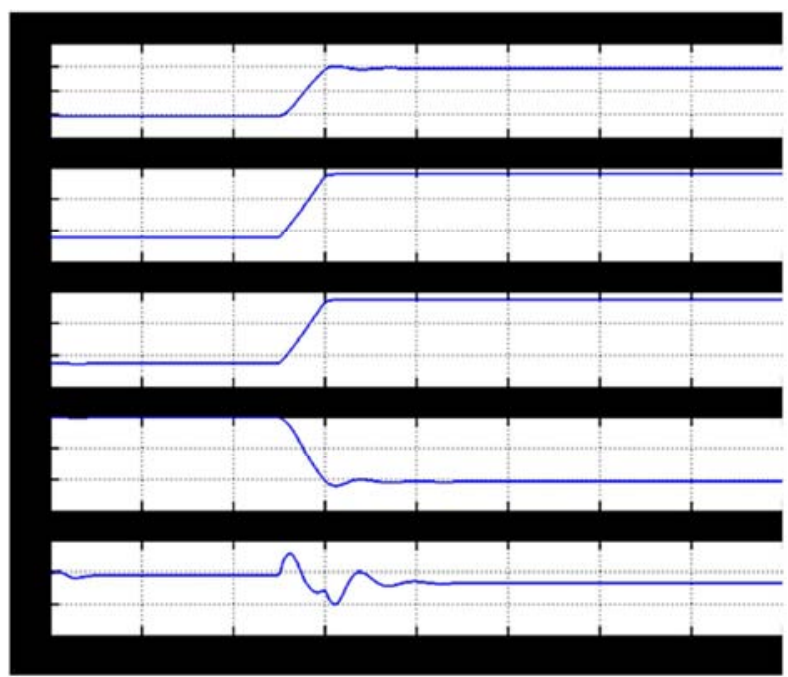

Figure 11. Active Power w.r.t time (With UPFC)

Reactive Power (MVAR) along y axis on bus no 1 to bus no 5

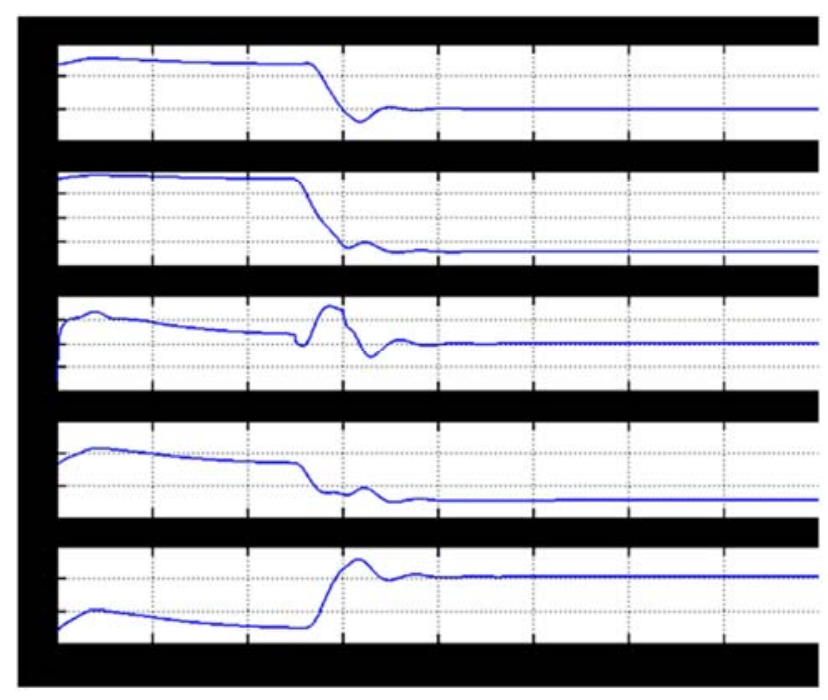

Figure 12. Reactive power w.r.t time (With UPFC).

\subsection{Remarks}

Active power on all the buses is changed. On bus 1 it becomes 195MW and on bus 4 it is reduced from $900 \mathrm{MW}$ to $800 \mathrm{MW}$, thus preventing transformer Tr 2 from overloading. This is a great advantage o UPFC. We can easily control the 
direction of active power in a power system. This was a basic example which is easy to understand. UPFC performs equally well in complex power network.

\subsection{Voltage Regulation of 500kv Transmission System}

In this section, connection of complex network with different transmission lines and power stations, and provide an overall analysis of pu levels on the system bus. The following is a system designed for analysis. The above system has 4 transmission lines. All lines have a UPFC. It can be seen that the effects of UPFC on bus voltage and active and reactive power flow and voltage regulation. Connect all UPFC first and then bypass all UPFC for simulation. The list of readings is shown in the table.

Table 1. Voltage Regulations.

\begin{tabular}{lll}
\hline Bus Number & With UPFC & Without UPFC \\
\hline 1 & 1.001 & 1.017 \\
2 & 1.003 & 1.017 \\
3 & 1.002 & 1.008 \\
4 & 0.9894 & 0.9912 \\
5 & 0.9985 & 1.001 \\
6 & 0 & 1.013 \\
7 & 1.003 & 1.008 \\
8 & 1.002 & 0.9912 \\
9 & 0.9894 & 1.001 \\
10 & 0.9985 & 0 \\
11 & 1.001 & 1.017 \\
12 & 0.9885 & 0 \\
13 & 1.003 & 1.013 \\
14 & 1.002 & 1.013 \\
15 & 0.9894 & 1.008 \\
16 & 0.9985 & 1.001 \\
17 & 0 & 1.013 \\
18 & 1.003 & 1.008 \\
19 & 1.002 & 1.099 \\
20 & 0.9884 & 1.002 \\
\hline
\end{tabular}

\subsection{Remarks}

As can be seen from the table, when the UPFC is not used, the voltage on different bus is not very close to $1 \mathrm{pu}$. On the other hand when UPFC is connected, the voltage on the bus is very close to $1 \mathrm{pu}$. This shows that UPFC is very helpful for in keeping the voltage close to 1 despite the heavy load.

\subsection{Stability of 500kv Transmission System}

Suppose that in the above system, a $65 \mathrm{~km}$ line is out of service due to a failure or repair purpose. Now due to dynamic changes, the system will certainly become unstable or unstable and unbalanced. As a result, the voltage on all buses will change drastically and may cause undesirable damage. UPFC can solve this problem. The UPFC maintains the voltage across all buses and reduces oscillations due to uneven power system variations. This is shown in the simulation. The circuit breaker trips after 1 second. Circuit breakers are used to remove a line from the system.

\subsection{Voltage Without UPFC (Observations)}

Voltage (pu) along y axis on bus no 1 to bus no 5

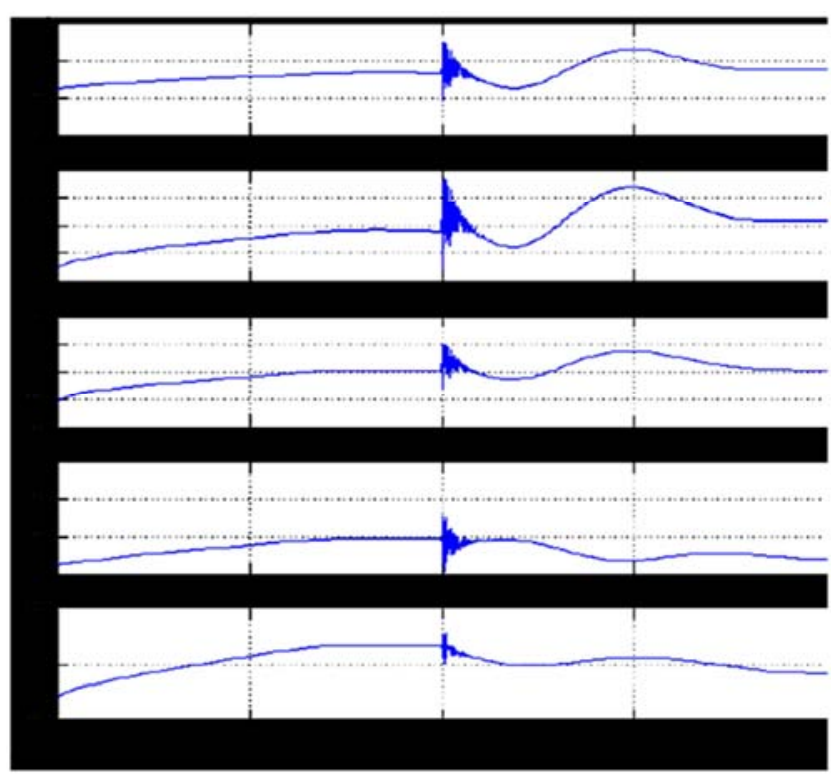

Figure 13. Bus voltages without UPFC.

\subsection{Voltage with UPFC (Observations)}

Voltage (pu) along y axis on bus no 1 to bus no 5

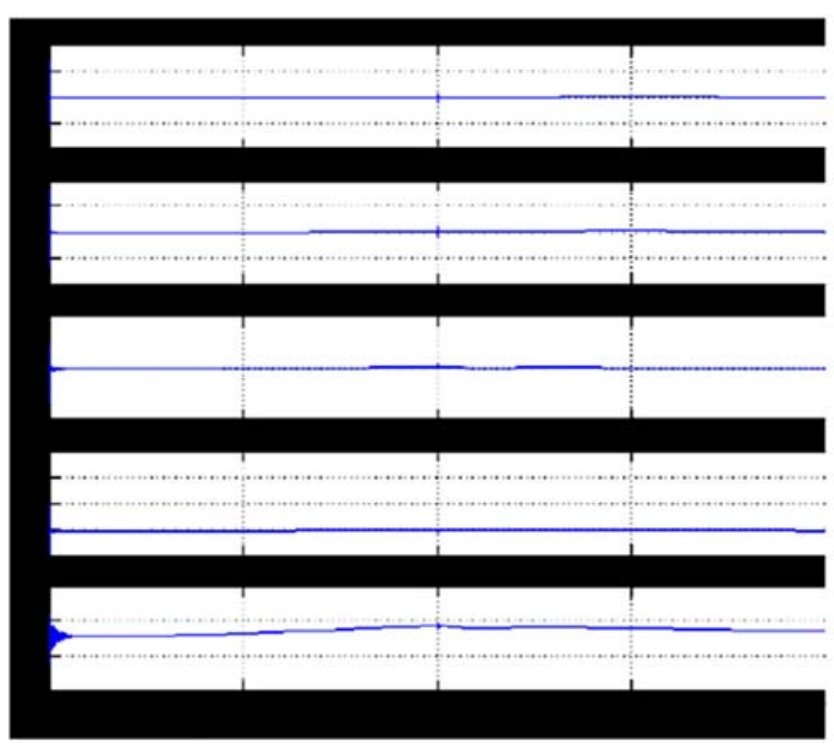

Figure 14. Bus Voltages with UPFC.

\subsection{Remarks}

It can be seen that a line out of the system within 1 second, the system voltage serious oscillation. But for the UPFC, the system voltage has not changed, is still close to $1 \mathrm{pu}$

\section{Conclusion}

In this paper the impact of UPFC on a $500 \mathrm{kv}$ transmission system has been studied. It can be observe that UPFC can control the direction of low power. UPFC increases the active power of the connected line. Therefore, it can control the flow of active power and prevent congestion in transmission system. In this way, the performance of the power system 
will increase with UPFC. This is the first goal that have achieved successfully.

In the second sections it can be observe that systems without UPFC, the voltages on the different buses are not very close to $1 \mathrm{pu}$. However, when UPFC is connected to systems, the bus voltage is very close to $1 \mathrm{pu}$. This proves that UPFC is very useful and suitable for voltage regulation. This will improve the performance of the power system. This is second goal of success.

It can be conclude that UPFC can control the amount and flow of active power, to achieve voltage regulation and improve system stability. Therefore UPFC is very useful for improving the performance of power systems.

\section{References}

[1] John J. Grainger, William D. Stevenson, -Power System Analysisl, Mittal Press, New Delhi India.

[2] Muhammad H. Rashid, -Power Electronics Circuits Devices \& Applications, 3ed.

[3] Flexible AC Transmission Systems: Modelling and ControlXiao-Ping Zhang, Christian Rehtanz, Bikash Pal.

[4] Juergen Schlabbach, Karl-Heinz Rofalski, -Power System Engineeringl, WILEY VCH Verlag GmbH \& Co. KgaA.

[5] Karris, -Introduction to Simulink with Engineering Applicationsll, Orchard Publications 2008.
[6] FACTS CONTROLLERSIN POWER TRANSMISSION AND DISTRIBUTION- K. R. Padiyar.

[7] S. Babaei, S. Bhattacharya, "Control Structure for LineFrequency-Switched STATCOMs under System Faults", proc. 2013 IEEE Energy Conversion Congress and Exposition (ECCE), pp. 2605-2612.

[8] Dynamic Modeling and Control of UPFC for Power Flow Control Procedia Technology, Volume 21, 2015, pp. 581-588.

[9] http://www.energy.siemens.com/hq/en/power transmission/facts/.

[10] http://www.energy.siemens.com/hq/pool/hq/powertransmissio n/FACTS/FACTS_Technology_.pdf.

[11] S. Muthukrishnan and Dr. A. Nirmal Kumar, "Comparison of Simulation and Experimental Results of UPFC used for Power Quality Improvement", International Journal of Computer and Electrical Engineering, Vol. 2, No. 3, June, 2010.

[12] Ali Ajami, S. H. Hosseini, and G. B. Gharehpetian, "Modelling and Controlling of UPFC for Power System Transient Studies", ECTI TRANSACTIONS ON ELECTRICAL ENG., ELECTRONICS, AND COMMUNICATIONS VOL. 5, NO. 2 August 2007.

[13] S. Tara kalyani, g. Tulasiram das, "simulation of real and reactive power flow control with UPFC connected to a transmission line", journal of theoretical and applied information technology.

[14] UPFC with series and shunt FACTS controllers for the economic operation of a power system Ain Shams Engineering Journal, Volume 5, Issue 3, 2014. 